\title{
Automatic Identification of Ficus deltoidea Jack (Moraceae) Varieties Based on Leaf
}

\author{
A Fakhri A Nasir ${ }^{1}$, M Nordin A Rahman ${ }^{1}$, Nashriyah Mat $^{2} \&$ A Rasid Mamat ${ }^{1}$ \\ ${ }^{1}$ Faculty of Informatics and Computing, Universiti Sultan Zainal Abidin, Tembila Campus, 22200 Besut, \\ Terengganu \\ ${ }^{2}$ Faculty of Agriculture, Biotechnology and Food Science, Universiti Sultan Zainal Abidin, Tembila Campus, \\ 22200 Besut, Terengganu \\ Correspondence: M Nordin A Rahman, Faculty of Informatics and Computing, Universiti Sultan Zainal Abidin, \\ Tembila Campus, 22200 Besut, Terengganu. Tel: 6-096-993-207. E-mail: mohdnabd@unisza.edu.my
}

Received: June 29, $2014 \quad$ Accepted: July 4, $2014 \quad$ Online Published: August 17, 2014

doi:10.5539/mas.v8n5p121 URL: http://dx.doi.org/10.5539/mas.v8n5p121

The research is financed by the Ministry of Education Malaysia.

\begin{abstract}
Currently, the traditional method used to identify Ficus deltoidea Jack (Moraceae) varieties require the plant taxonomists to observe and examine the leaf morphology of herbarium or live specimens. An automated variety identification system would ease the herbs collector to carry out valuable plant identification work. In this paper, a model for $F$. deltoidea varieties identification based on their leaf shape, color and texture was developed. Five different varieties of $F$. deltoidea were used in the proposed work with sixty nine sample data collected for each of varieties. First, the $F$. deltoidea leaves were plucked and the picture of leaves is then taken by a digital scanner in the format of JPEG. For leaf shape, a total of fourteen shape features were extracted based on basic geometric features. The mean of different color channels was calculated in leaf color feature extraction. Furthermore, four texture features based on gray-level co-occurrence matrix was implemented to extract leaf texture properties. By using the leaf structure, a set of three different leaf properties which are leaf shape, color and texture features was extracted. The features weight is then calculated using eigenvalues coefficient in principal component analysis. The best principal components are retained for identification experiments. Lastly, Nearest Neighbor with Euclidean distance was used in variety identification based on three different leaf properties mentioned above. The effectiveness of different leaf features are demonstrated in the identification experiment.
\end{abstract}

Keywords: Ficus deltoidea Jack, plant leaf identification, content-based image retrieval, pattern recognition, image processing

\section{Introduction}

Herb plants have been used through much of human history as sources of food or food additive, medicine, beauty enhancers used in cosmetic ingredients and fragrances. The use of herbs as medicine has a long history, starting from the Greek civilization in the West and the Arabic, Chinese and Indian civilizations in the East (Ramlan, 2003). Herbs as traditional medicine is still widely practiced today and in modern medicine, it is recognizes as a form of alternative medicine. Many allopathic medicines, which are produced synthetically, also derived from plants such as quinine for malaria, quinidine for heart arrhythmia from Cinchona spp and digoxin for heart failure from Digitalis spp (Ramlan, 2003).

Ficus deltoidea Jack (Moraceae) or mistletoe fig (common name) or locally known as 'Mas Cotek' among the Malays, is recognized as Malaysian herb plants (Hean et al., 2011). F. deltoidea is a native and widely distributed throughout Malaysia, Thailand, Sumatra, Java, Kalimantan, Sulawesi, and Moluccasa (USDA, 2007). In Malay traditional medicine, the dried $F$. deltoidea leaves are marketed as an herbal tea. The decoction of the leaves is believed to improve blood circulation and have aphrodisiac activity and antioxidant and antidiabetic properties (Norhaniza et al., 2007; Sulaiman et al., 2008; Adam et al., 2011). Moreover, other approaches revealed that $F$. deltoidea leaves is a potential alternative medicine to strengthen the uterus for women after birth (Sulaiman et al., 
2008) and effective on enhancement of wound healing (Abdulla et al., 2010).

Figs or Ficus plants originated in Asia Minor and can be found throughout Mediterranean, Indian subcontinent, Latin America, Texas, Southern California, until the Far East such as in the Malaysian tropical rain forest (USDA, 2007). It is one of the largest genera of flowering plants with six traditional subgenera that are recognized based on morphology and distribution (Lansky \& Paavilainen, 2011). One of the species that included in this genus is Ficus deltoidea Jack (Latin name). Seven out of 15 recognized varieties of $F$. deltoidea found in Peninsular Malaysia namely var. deltoidea, var. angustifolia, var. trengganuensis, var. bilobata, var. intermedia, var. kunstleri and var. motleyana (Kochummen, 1978; Turner, 1995). F. deltoidea is a large shrub or small tree with aerial roots often begins its life as an epiphyte plant. It is also cultivated in various parts of the world as a houseplant or as an ornamental shrub. The name 'Mas Cotek' is given in Peninsular Malaysia because there are fine spots with gold in colour on the surface of each leaves. Generally, the scopes of the study can be specified as modeling an automatic identification for $F$. deltoidea varieties recognition.

\section{Problem Statements}

Traditionally, herbs have been collected for use from wild areas (Ramlan, 2003). For large scale production, this presents an unfeasible solution due to the lack of reliable supply. Continuous harvesting of wild sources will lead to species endangerment and extinction. Agricultural cropping of herbs as specialty crops can ensure high quality herbal by correct herb identification. Correct herb identification is essential as many herbal species come in many varieties which have similar appearances but have different usages in traditional medicine. For example, $F$. deltoidea var. deltoidea and F. deltoidea var. angustifolia are two of Ficus deltoidea Jack (Moraceae) varieties which have more or less similar morphological appearances in the eye of amateur herbs collector. However, according to study made by Nihayah et al. (2012), these two varieties have different mineral content in leaf, whereby $F$. deltoidea var. deltoidea contain high amount of magnesium, manganese and potassium compared to $F$. deltoidea var. angustifolia. As a conclusion, $F$. deltoidea var. deltoidea leaf is more suitable to be served as a tea drink.

Based on the importance of in herb plant to medical practitioners, recent development especially for Ficus deltoidea Jack (Moraceae) indicates the need to provide a computer-based identification system in order to get correct identification. Currently, the traditional method used to identify F. deltoidea have lots of disadvantages which leads to time consuming, less efficient, troublesome task for nonprofessional and sometimes identification task is too complex. In recent years, the existence of sophisticated technologies such as digital cameras and portable computers has lead to an increasing interest in automating the process of plant species identification. Although there are various types of computer algorithms and databases for plant species identification has been built to speed up taxonomists work, the computer algorithms and databases in herb plant species are very hard to find. In case of $F$. deltoidea plant, there is no image database found in the literature. Plant species identification for herb plant becomes one of the main challenging tasks in computer vision due to lack of proper models or representations. As stated in detail reviews of plant species identification research by Cope et al. (2012), different features are often needed to distinguish different categories of plant. For example, whilst leaf shape may be sufficient to distinguish between some species, other species may have very similar leaf shapes to each other, but have different colored leaves. No single feature, or kind of feature, may be sufficient to separate all the categories, making feature selection a challenging problem (Cope et al., 2012). For this reason, research to get a right model to identify the herbs plant species is essential. This paper objective is to emphasizes the approach of automatic identification model for Ficus deltoidea Jack (Moraceae) varieties. Three feature selection approaches which are leaf shape, leaf color and leaf texture are used and explained in the next section.

\section{The Model}

Many models have been used for plant species identification that most of them follow the same general steps in content-based image retrieval. The process started with image acquisition, followed by preprocessing, segmentation and features extraction. Finally, the identification or commonly known as classification process will look up into a database to find the similarity of the query leaf image. According to Ab Jabal et al. (2013), two important consideration has to be critically made in developing plant species identification which are in features extraction and classification phase. Other phase considered as less important because it is reflected on image acquisition technique. Almost all previous image acquisition approaches are implemented in the same manner. For example Lee \& Chen (2006) and Du et al. (2007) used a digital scanner for leaf image capturing and therefore preprocessing and segmentation process done in the same manner.

Leaf shape is a prominent feature that most people use to recognize and classify a plant (Hossain \& Amin, 2010). Wu et al. (2007), Hossain \& Amin (2010), Kadir et al. (2011) and Zulkifli et al. (2011) had stated that diameter, 
physiological length, physiological width, leaf area and perimeter are basic geometry information can be extract from the leaf shape. In addition, leaf color (using mean of RGB color channel), textures (using contrast, correlation and homogeneity) and vein are also considered as important features (Kadir et al., 2011). All these features are useful for recognition of leaf image. For this case study, vein features are not used due to the technique of image acquisition. By using a digital scanner, the leaf vein structures are not clearly seen. A light bank is required to get the clearer vision of leaf vein.

The features extraction process for $F$. deltoidea varietal identification is referred from the works (Lee \& Chen, 2006; Wu et al., 2007; Hossain \& Amin, 2010; Zulkifli et al., 2011; Fotopoulou et al., 2013; Kadir et al., 2011; Najjar \& Zagrouba, 2012). The used of Principal Component Analysis (PCA) and Nearest Neighbor (NN) are referred from (Lee \& Chen, 2006; Du et al., 2007; Wu et al., 2007; Kadir et al., 2012). Figure 1 shows the block diagram for the $F$. deltoidea varietal identification model.

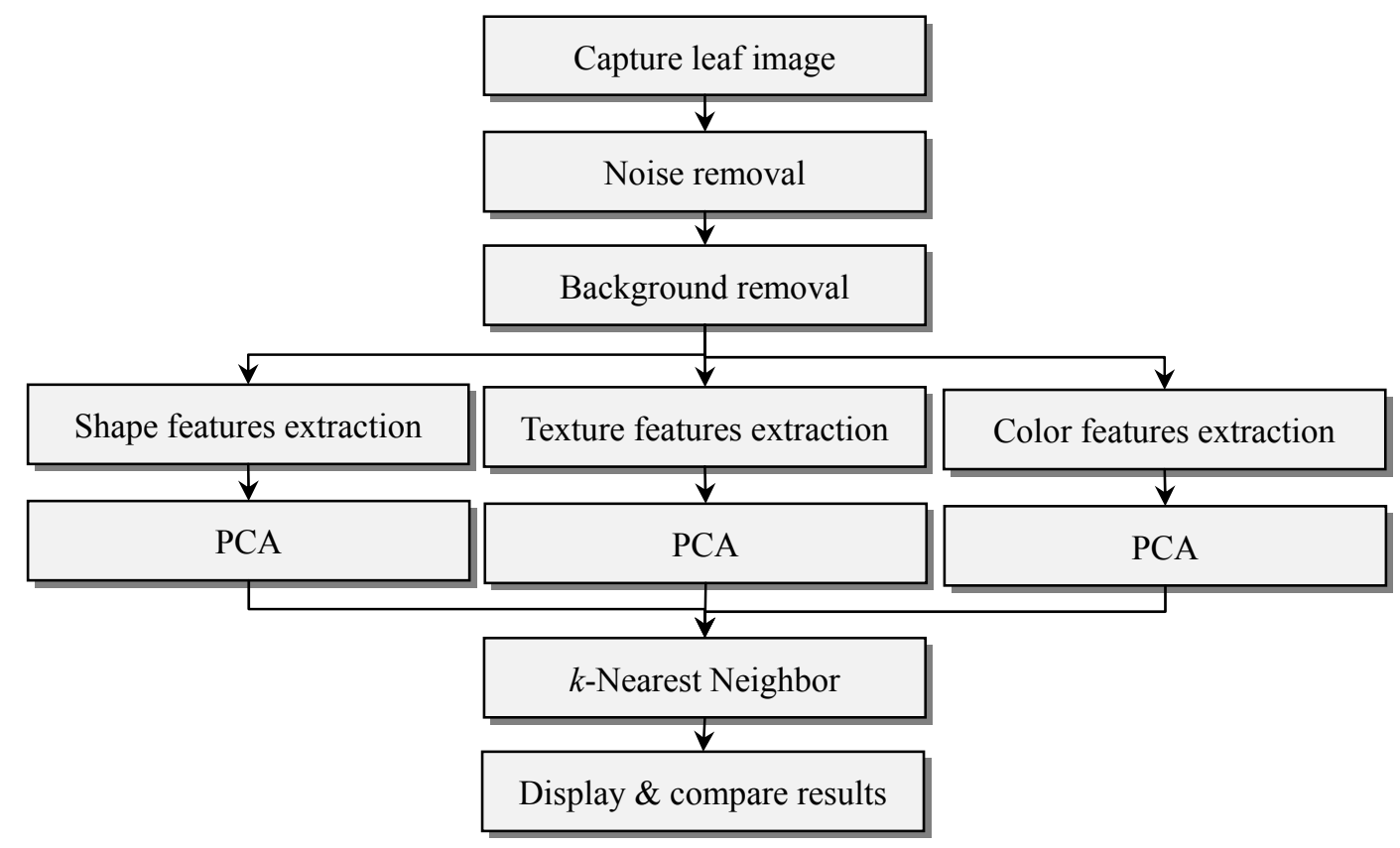

Figure 1. Block diagram of the $F$. deltoidea varietal identification model

\subsection{Capture Leaf Image}

The current study was carried out on five varieties only excluded for var. montleya and var. intermedia due to unavailability of these two varieties in the Germplasm Living Collection at the Tembila Campus of Universiti Sultan Zainal Abidin. Since there is no F. deltoidea leaf image available elsewhere in literature, the leaf image database used in the following work was collected and built by ourselves. Firstly, the leaves from each plant are plucked. The single leaf was placed on a white A4 size paper, and then the picture of the leaf was taken with a digital scanner. This process generates a standard leaf image in JPEG format with the white background. For this time, a total of $345 \mathrm{~F}$. deltoidea leaf images that consisted of 69 leaf images for each of variety have been collected. The representative sample images for the five varieties are shown in Figure 2.

\subsection{Noise Removal}

Digital images are prone to a variety of types of noise. Noise is the result of errors in the image acquisition process that result in pixel values that do not reflect the true intensities of the real scene. In this case, the image is acquired directly in a digital format. The leaf is inserted to digital scanner may have some dirt that come out from the leaf itself. In order to remove noise median filtering with $3 \times 3$ neighborhood is used. Median filtering is similar to an averaging filter, in that each output pixel is set to an average of the pixel values in the neighborhood of the corresponding input pixel. 


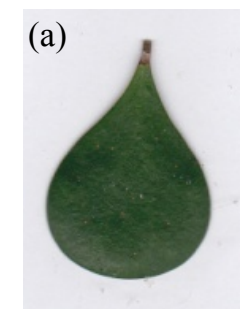

(b)

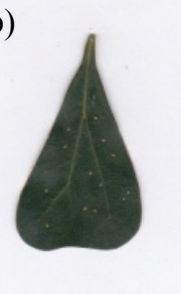

(c)

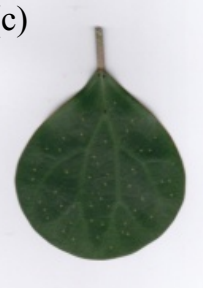

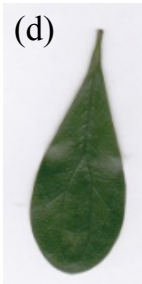

(e)

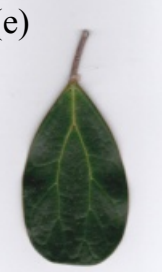

Figure 2. Variety of F. deltoidea in the leaf database, (a) var. deltoidea, (b) var. bilobata, (c) var. kunstleri, (d) var. angustifolia, and (e) var. trengganuensis

\subsection{Background Removal}

As mentioned before, the captured of $F$. deltoidea leaf image gives an image of leaf with an almost white background with interference by scanner lighting (see Figure 2). In order to remove the white background, segmentation process by using thresholding method based on histogram is used. First, the RGB leaf image is converted to grey-level image by the following equation:

$$
\text { Grey }=0.299 * \mathrm{R}+0.578 * \mathrm{G}+0.114 * \mathrm{~B}
$$

Where; R, G, B correspond to the color of the pixel, respectively. The gray-scale image for plant leaf is shown in Figure 4(b).

The level to convert grayscale into binary was determined according to grayscale histogram. We accumulated the grayscale pixel values for 345 leaves and divided them by 345 , the number of leaves. The average histogram to grayscale of 345 leaf images is shown as Figure 3. There are two peaks in the grayscale histogram. The left peak that refers to pixels was consisted of the leaf while the right peak that refers to pixels consisted of the white background (with interference by scanner lighting). The lowest peak between left peak and right peaks is approximately the value of 160 on the average. Therefore, the level of $0.6275(160 / 255)$ is applied. The output image replaced all pixels in the input image with greater than the level by the value of 1 and replaced all other pixels by the value of 0 .

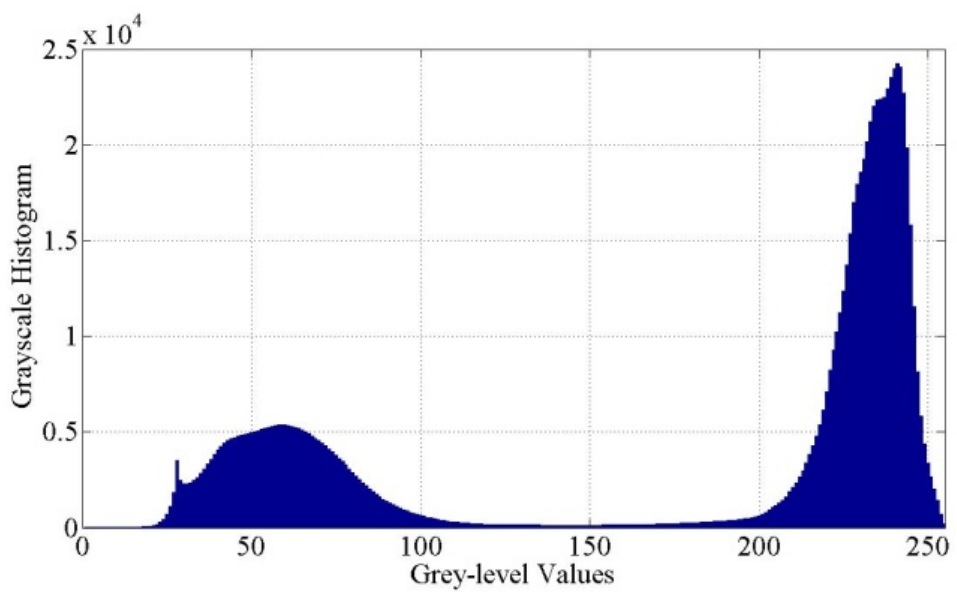

Figure 3. Average grey-level values for 345 leaf images

After image thresholding, some defects might be presented in the leaf images for example some parts of objects might be misclassified as background and some small regions of background might be mistakenly segmented as objects. Consequently, image opening and image closing of mathematical morphology are used for processing image segmented by thresholding. Image opening involves reserving the unsegmented parts of objects using first image dilation, by merging neighboring pixels of an object into the object and the image erosion, by removing boundary pixels of objects. On the contrary, image closing is image erosion followed by image dilation in order to eliminate the unsegmented parts of background. Let $E$ be a Euclidean distance space or an integer grid, $A$ is a binary image in $E$ where $B_{z}$ is the translation of $B$ by a vector $z$, and $B^{s}$ denotes the symmetric of $B$. The 
mathematical definition of dilation for binary images is defined as follows:

$$
A \oplus B=\left\{z \in E \mid\left(B^{s}\right) \cap A \neq \varnothing\right\}
$$

The erosion of the binary image $A$ is defined by:

$$
A \ominus B=\left\{z \in E \mid B_{z} \subseteq A\right\}
$$

The opening of a set (binary image) $A$ by a structuring element $B$ is the dilation followed by the erosion of that set which is:

$$
A \cdot B=(A \ominus B) \oplus B
$$

The closing of a set (binary image) $A$ by a structuring element $B$ is the erosion followed by the dilation of that set which is:

$$
A \cdot B=(A \oplus B) \ominus B
$$

Notice that there existed some variances on length of leaf petiole. To keep the precision of leaf shape features extraction, these leaf petioles should be further removed from the obtained binary images. Here, the process of image closing operation to binary images is considered. By performing the closing operation with proper structuring element, the leaf petioles removal can be achieved successfully while preserving the main shape characteristics of leaf objects. The result of leaf petiole removal of binary image is shown in Figure 4(e).
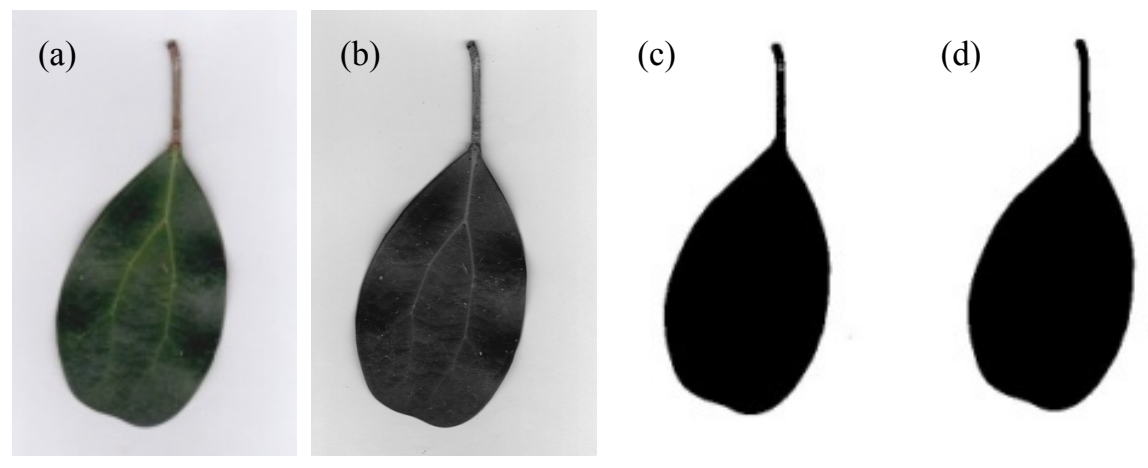

(e)

Figure 4. The processed leaf image (example on var. trengganuensis), (a) original image, (b) gray image, (c) binary image, (d) smooth binary image, and (e) leaf petiole removal

The leaf in Figure 4(e) is then used for shape features extraction. For color and texture features extraction, the leaf in Figure 4(e) is also used but the black region which is leaf region is converted back to the original RGB color.

\subsection{Shape Features Extraction}

For efficient shape feature extraction, a regionprops function in Matlab is used which calculates the region properties. In this paper, 5 basic region features; area, convex area, perimeter, major axis length, minor axis length and diameter are extracted using this function. Another nine features are then derived from the previous five basic features. In total, 14 digital features are extracted for each of the leaf image.

1) Area: The actual number of pixels in the region. It is denoted as A.

2) Convex Area: The area of convex hull of the region. The convex area is greater than or equal to area of the region. It is denoted as CA.

3) Major Axis Length: Major Axis Length is defined as the length (in pixels) of the major axis of the eclipse that has the same normalized second central moments as the region. It is denoted as MAL.

4) Minor Axis Length: Minor Axis Length is defined as the length (in pixels) of the minor axis of the eclipse. It is denoted as MIL.

5) Perimeter: The distance around the boundary region. It is calculated by counting the distance between each adjoining pair of pixels around the border of the region. It is denoted as $\mathrm{P}$.

Based on 5 basic features introduced previously, another 9 features are defined for leaf recognition. 
6) Diameter: Scalar that specifies the diameter of a circle with the same area as a region. It is computed as $4 \mathrm{~A} / \pi$, where $\mathrm{A}$ is the leaf area.

7) Solidity: This feature is derived from convex hull and defined as A/CA, where $\mathrm{A}$ is the area of the leaf and CA is the area of convex hull.

8) Roundness: The roundness or circularity ratio is defined as A/P2, where $A$ is the leaf area and $P$ is the leaf perimeter.

9) Aspect Ratio: The aspect ratio is a ratio between the major axis length and the minor axis length, MAL/MIL.

10) Rectangularity: This feature describes the similarity between a leaf and a rectangle. It is defined as MAL*MIL/A, where MAL is major axis length, MIL is minor axis length and A is the leaf area.

11) Form Factor: It is defined as $4 \pi \mathrm{A} / \mathrm{P} 2$, where $\mathrm{A}$ is the leaf area and $\mathrm{P}$ is the leaf perimeter. This feature is used to describe the different between a leaf and a circle.

12) Eccentricity: This feature is used to differentiate the rounded leaf and the long one. The eccentricity is defined as MIL/MAL, where MIL is the minor axis length of the leaf and MAL is the major axis length of the leaf.

13) Perimeter Ratio to Diameter: It is represented as the ratio of the leaf perimeter $P$ and leaf diameter $D$. This is calculated by $\mathrm{P} / \mathrm{D}$.

14) Perimeter Ratio of Major Axis Length and Minor Axis Length: This feature is defined as the ratio of leaf perimeter $\mathrm{P}$ and the sum of major axis length and minor axis length, $\mathrm{P} /(\mathrm{MAL}+\mathrm{MIL})$.

\subsection{Color Features Extraction}

The mean or average for each of color channel value is extracted in this process. Four color channels used in this implementation consists of RGB, HSV, Lab and YIQ. Mean of grayscale value is also used. First, the leaf in Figure 4(e) is converted back to the original RGB color. Then, A colormap functions in Matlab is used to convert the orginal RGB leaf image into each of color channels mentioned. The mean for each color channel is calculated. For example, in RGB color, mean for Red, Green and Blue values are calculated separately and this process continues to the other color channels. In this way, 13 color features are extracted which are mean value of grayscale, R, G, B, H, S, V, Y, I, Q, L, a and b.

\subsection{Texture Features Extraction}

A statistical method of examining texture that considers the spatial relationship of pixels is the gray-level co-occurrence matrix (GLCM), also known as the gray-level spatial dependence matrix. The GLCM functions characterize the texture of an image by calculating how often pairs of pixel with specific values and in a specified spatial relationship occur in an image, creating a GLCM, and then extracting statistical measures from this matrix. In Matlab, graycoprops function uses the normalized GLCM to calculate contrast, correlation, energy and homogeneity. These four properties are extracted for texture features. Firstly, the leaf in Figure 4(e) is converted back to the original RGB color. The image is then converted to grey-level image. By using default graycomatrix function, GLCM matrix is then created. Lastly, by using the normalized GLCM, four texture features are finally extracted.

\subsection{Principal Component Analysis}

Principal Component Analysis is a statistical method to reduce the dimension of variables. It is useful when implemented on a large number of variables with possibly having some redundancy in those variables. In this case, redundancy means that some of the variables are correlated with one another. Because of this redundancy, it should be possible to reduce the observe variables into a smaller number of principal components that will account for most of the variance in the observed variables (O'Rourke et al., 2005).

Technically, a principal component can be defined as a linear combination of optimally-weighted observed variables. The general form for the formula to compute scores on the first component extracted in a principal component analysis is as below:

$$
C_{1}=b_{11}\left(X_{1}\right)+b_{12}\left(X_{2}\right)+\ldots b_{1 \mathrm{p}}\left(X_{\mathrm{p}}\right)
$$

where; $C_{1}$ is the subject's score on principal component (the first component extracted), $b_{1 \mathrm{p}}$ is the regression coefficient (or weight) for observed variable $p$, as used in creating first principal component, and $X_{\mathrm{p}}$ is the subject score on observed variable $p$. To calculate the regression coefficient $\left(b_{1 \mathrm{p}}\right)$, there are other four steps must be completed in PCA. 1) Calculate mean for all of the data, 2) standardized the data by subtracting the data with mean, 3) calculate the covariance of the data and 4) calculate the eigenvalues and the eigenvectors based on the 
covariance matrix. The coefficient is then obtained from the eigenvalues. Finally, the coefficient, $b_{1 \mathrm{p}}$ is then placed in above equation.

The number of components extracted is equal to the number of variables being analyzed. In general, the first few components will account for meaningful amounts of variance and the later components will tend to account for only trivial variance. Therefore, the next step is to determine how many meaningful components should be retained for classification. Four criteria may be used in making this decision which is eigenvalue-one criterion, the scree test, the proportion of variance accounted and the interpretability criterion (O'Rourke et al., 2005). In this study, the scree test is considered to make this decision. Figure 5 shows the scree test plot for shape, color and texture features.
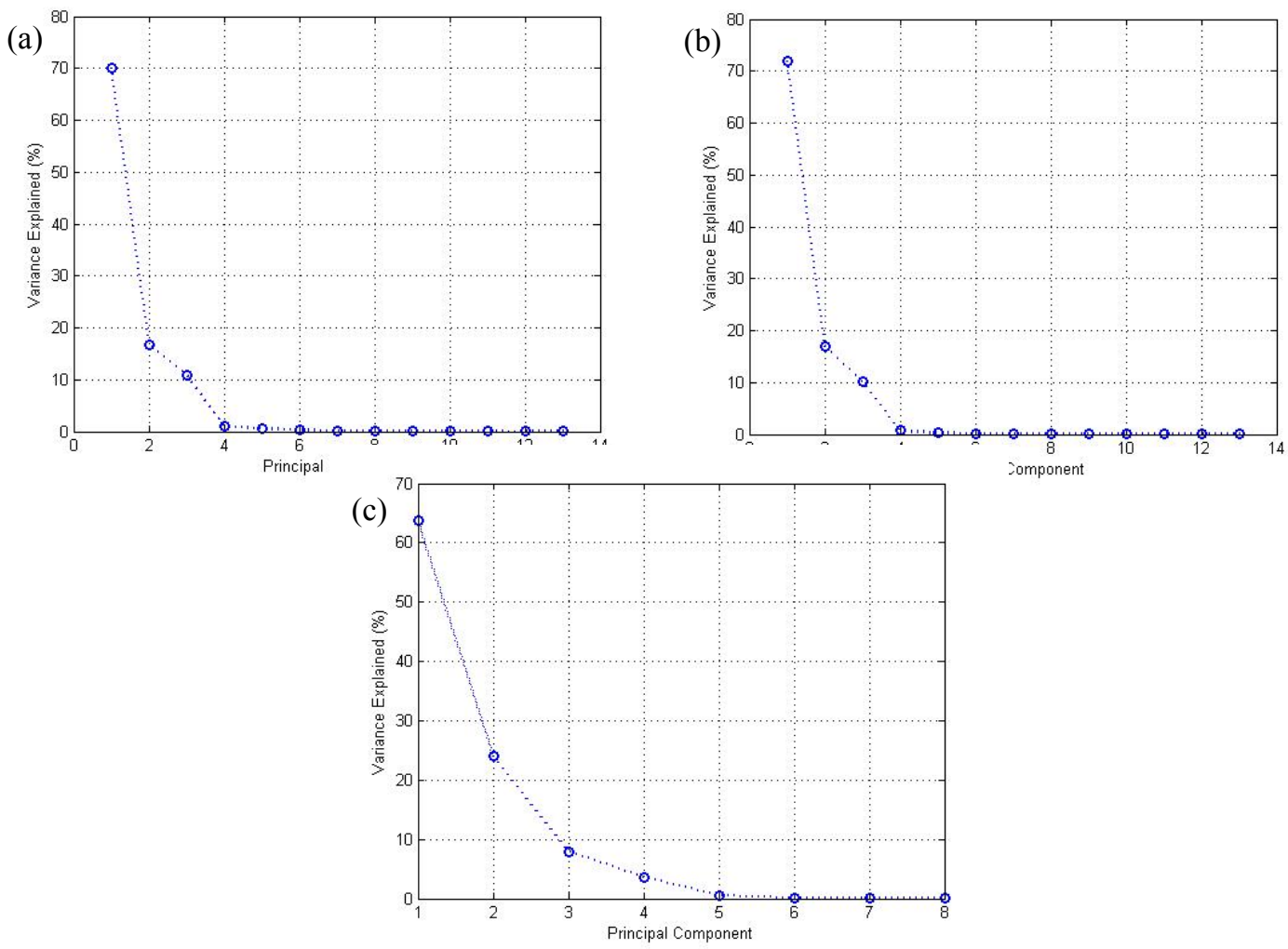

Figure 5. The scree test plot, (a) shape features, (b) color features, and (c) texture features

With the scree test, the eigenvalues (variance explained) associated with each component is plotted. To choose the few components, (Kaiser, 1960) recommend readers to find for a "break" between the components with relatively large eigenvalues and those with small eigenvalues. The components that appear before the break are assumed to be meaningful and are retained for next process. For this case, the "break" is appeared at principal component 3 for all of plots (see Figure 5), therefore only the principal component 1, principal component 2 and principal component 3 should be retained. In this work, principal component 1, principal component 2, principal component 3, single original features and combined original features for each of shape, texture and color are used in the identification experiments.

\subsection{Nearest Neighbor}

The Nearest Neighbors algorithm is a method for identifying objects based on closest training examples in the feature space. The Nearest Neighbors (NN) classification divides data into a test set and a training set. For each row of the test set, the $k$ nearest (in Euclidean distance) training set objects are found, and the identification is determined by majority vote. In Cartesian coordinates, if $p=\left(p_{1}, p_{2}, \ldots, p_{n}\right)$ and $q=\left(q_{1}, q_{2}, \ldots, q_{n}\right)$ are two points in Euclidean $n$-space, then the distance from $p$ to $q$, or from $\mathrm{q}$ to $\mathrm{p}$ is given by:

$$
d(p, q)=d(q, p)=\sqrt{\sum_{i=1}^{n}\left(q_{i}-p_{i}\right)^{2}}
$$




\section{Experimental Results}

In the experiment, the performance comparison of the $k$-NN classifier with the nearest neighbor (3-NN), (5-NN) and (7-NN) are executed. The odd number is used in order to avoid ties result. When using an even number, for example $k=2$, let say the two closet distance falls into class 1 and class 2 . Therefore, the result for this example is ties whereby $50 \%$ falls into class 1 and $50 \%$ falls in class 2 . Thus, even number is not used in this experiment. To each variety of $F$. deltoidea, all leaves image are pickup from database. If one image is selected as a query image, the rest will be testing image samples. In other words, this process namely leave-one-out cross-validation testing. In each of leaf features properties, the average recognition accuracy is calculated for each of test images. Figure 6, Figure 7 and Figure 8 show the recognition accuracy for shape, color and texture features respectively.

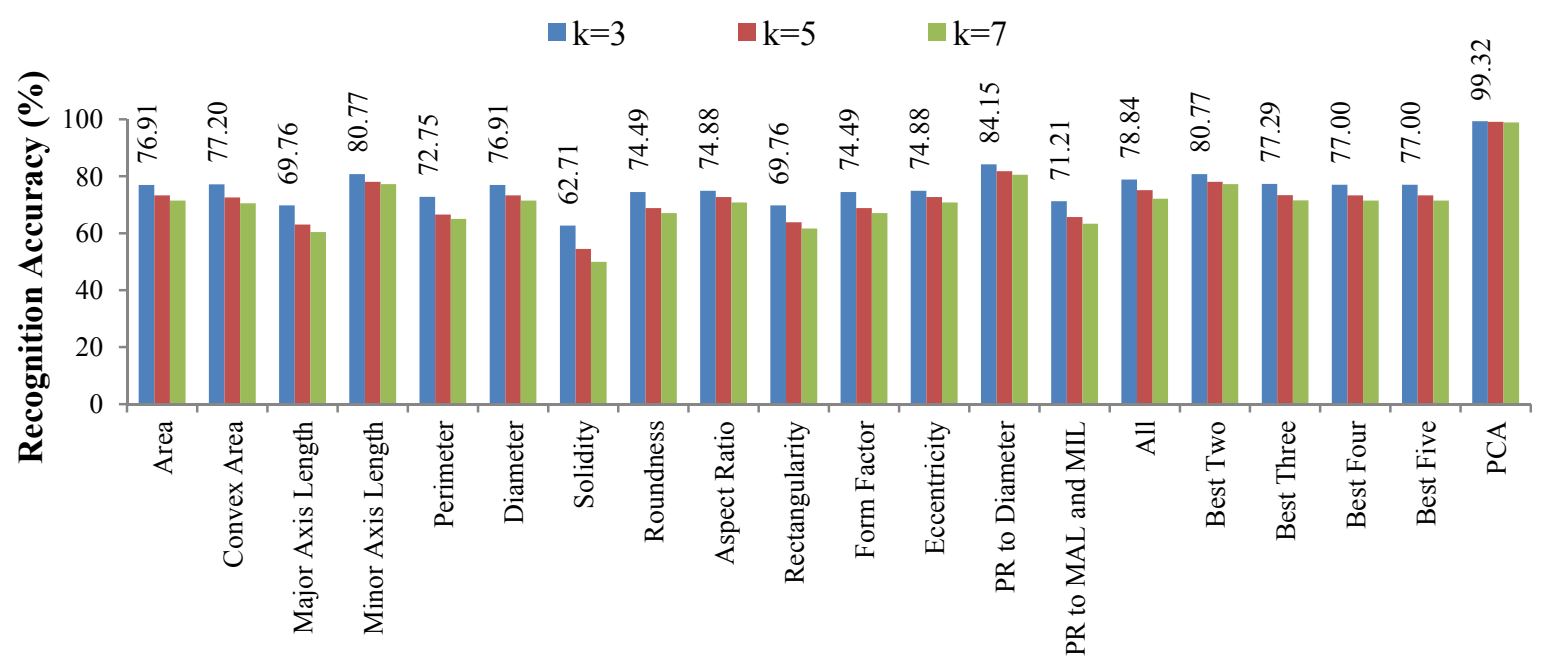

Shape Features

Figure 6. Average recognition accuracy for shape features

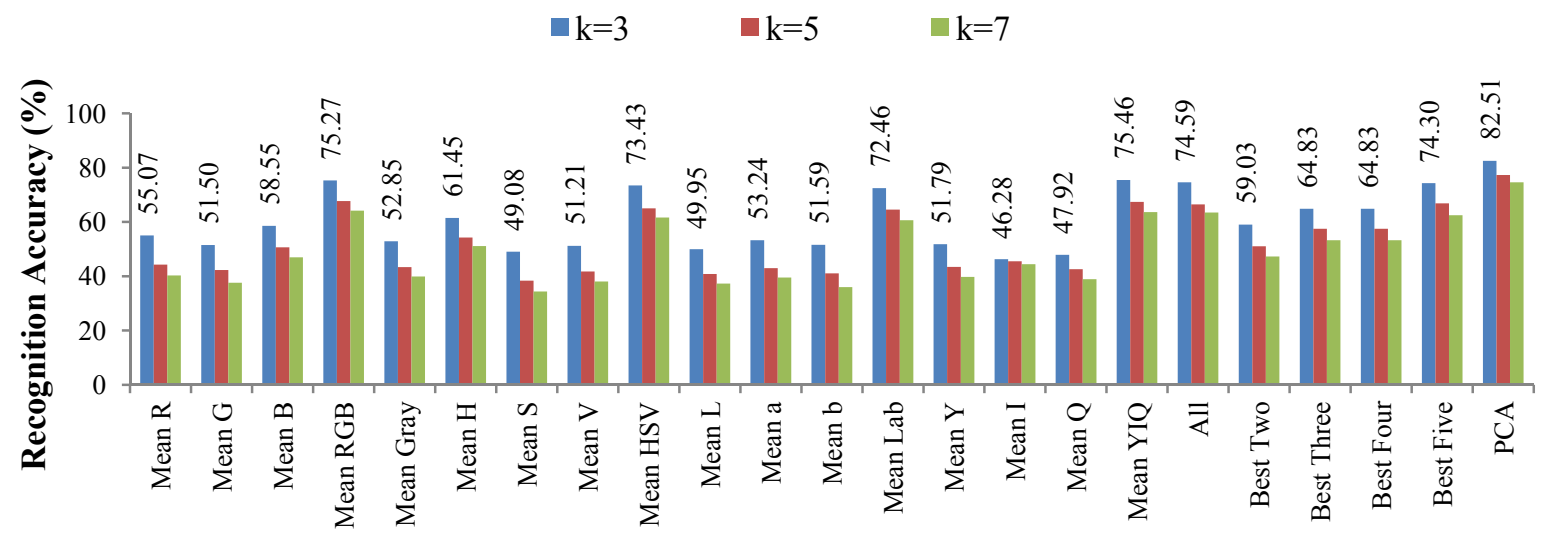

\section{Color Features}

Figure 7. Average recognition accuracy for color features 


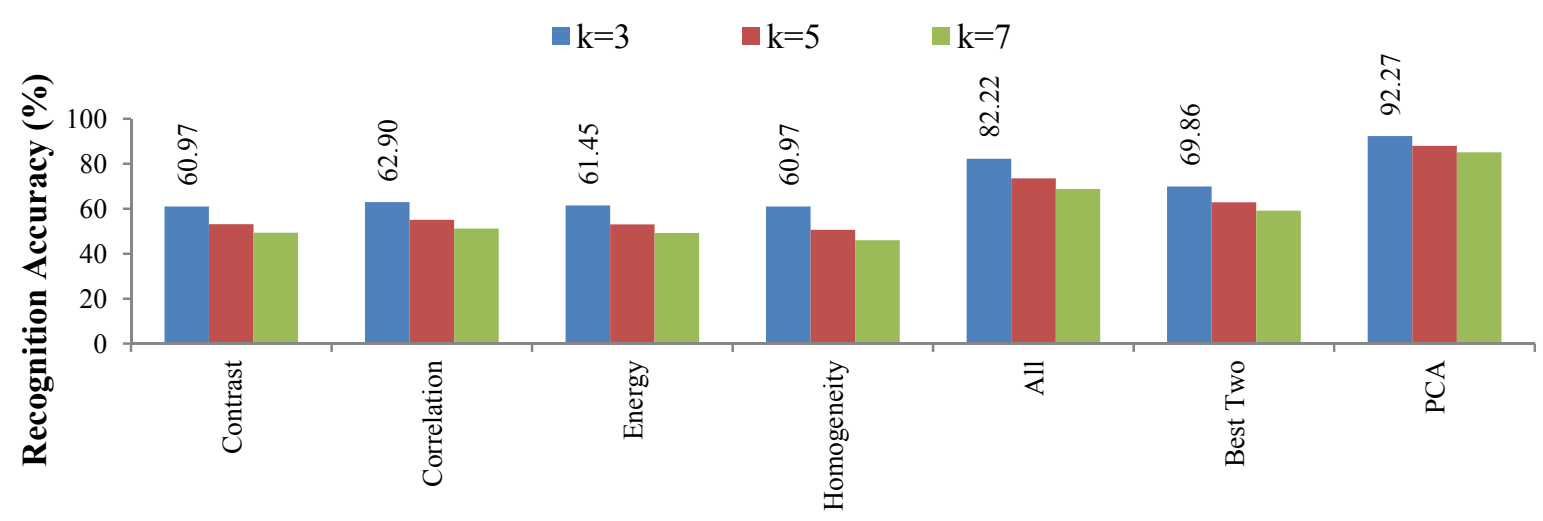

Texture Features

Figure 8. Average recognition accuracy for texture features

Based on Figure 6, Figure 7 and Figure 8, NN with $k=3$ is the best for all features. In shape features, perimeter ratio to diameter $(84.15 \%)$ is the best feature to distinguish five varieties of $F$. deltoidea followed by minor axis length $(80.77 \%)$. The recognition accuracy for combination of all shape features, the best two, best three, best four and best five features showed no continuous increment when adding more combined features. The result for PCA is the highest $(99.32 \%)$ with approaching to $100 \%$. As compared to perimeter ratio to diameter, the use of PCA is able to increase the performance using shape features for about $15.27 \%$.

According to Figure 7, mean $\mathrm{H}(61.45 \%)$ is the best single color features followed by mean B $(58.55 \%)$ and mean R (55.07\%). From this result, combinations of color mean features showed better performance than single feature. For example, the mean for $\mathrm{R}$ is $55.07 \%, \mathrm{G}$ is $51.50 \%$ and $\mathrm{B}$ is $58.55 \%$. When these three features are combined (mean RGB), the identification accuracy becomes more efficient. As the same to shape features, combination of all color features, the best two, best three, best four and best five features also showed no continuous increment when adding more combined features. The result for PCA is the highest which is $82.15 \%$. As compared to mean YIQ feature, the use of PCA is able to increase the performance using color features for about $8.14 \%$.

The correlation $(62.90 \%)$ showed the best recognition accuracy for texture analysis. Combination of all texture features is better than using single texture feature. PCA is the best results in this features which boost up 10.87\% recognition accuracy compared to the best original features. For clearer view on experimental results, the best recognition accuracy is summarized in Table 1.

Table 1. Summary of experimental results

\begin{tabular}{crc}
\hline Feature & The best original & PCA \\
\hline Shape & (Perimeter ratio to Diameter) $84.15 \%$ & $99.32 \%$ \\
Color & (mean YIQ) $75.46 \%$ & $82.51 \%$ \\
Texture & (All) $82.22 \%$ & $92.27 \%$ \\
\hline
\end{tabular}

\section{Conclusion}

This paper introduces an automatic $F$. deltoidea varietal identification model based on leaf shape, leaf color and leaf texture which replaced the traditional method that has many disadvantages. The experimental results showed that the use of leaf shape is much better to distinguish five varieties of $F$. deltoidea. In addition, the use of PCA is able to boost up the recognition accuracy. Finally, the use of 3-NN is better for this dataset. In order to generalize the model, the future works will focus on collecting more leaf images from var. montleya and var. intermedia to complete the seven $F$. deltoidea varieties that found in Malaysia. Finally, the model should be extended to include a graphical user interface to ease user. 


\section{Acknowledgments}

The authors duly acknowledged the permission of the Faculty of Agriculture, Biotechnology and Food Sciences Universiti Sultan Zainal Abidin (UniSZA), Besut, Malaysia for allowing us to pick and capture leaves of $F$. deltoidea at the Faculty Nursery in the Tembila Campus. Acknowledgement was also given to the nursery staff of the Faculty of Agriculture, Biotechnology and Food Sciences for their continuous support.

\section{References}

Ab Jabal, M.F., Hamid, S., Shuib, S., \& Ahmad, I. (2013). Leaf features extraction and recognition approaches to classify plant. Journal of Computer Science, $1295-1304$. http://dx.doi.org/10.3844/jessp.2013.1295.1304

Abdulla, M. A., Ahmed, K. A. A., Abu-Luhoom, F. M., \& Muhanid, M. (2010). Role of Ficus deltoidea extract in the enhancement of wound healing in experimental rats. Biomedical Research, 21(3), 241-245.

Adam, Z., Ismail, A., Khamis, S., Mokhtar, M. H. M., \& Hamid, M. (2011). Antihyperglycemic activity of F. deltoidea ethanolic extract in normal rats. Sains Malaysiana, 40(5), 489-495.

Cope, J. S., Corney, D., Clark, J. Y., Remagnino, P., \& Wilkin, P. (2012). Plant species identification using digital morphometrics: A review. Experts Systems with Applications, 39(8), $7562-7573$. http://dx.doi.org/10.1016/j.eswa.2012.01.073

Du, J. X., Wang, X. F., \& Zhang, G. J. (2007). Leaf shape based species recognition. Applied Mathematics and Computation, 185(2), 883-893. http://dx.doi.org/10.1016/j.amc.2006.07.072

Fotopoulou, F., Laskaris, N., Economou, G., \& Fotopoulos, S. (2013). Advanced leaf image retrieval via Multidimensional Embedding Sequence Similarity (MESS) method. Pattern Anal. Applic, 16(3), $381-392$. http://dx.doi.org/10.1007/s10044-011-0254-6

Hean, C. O., Rosnaini, M. Z., \& Pozi, M. (2011). Traditional knowledge of medicinal plants among the Malay villagers in kampung Mak Kemas, Terengganu, Malaysia. Studies on Ethno-Medicine, 5(3), 175-185.

Hossain, J., \& Amin, M. A. (2010). Leaf shape identification based plant biometrics. Proceedings of the Computer and Information Technology, 458-463. http://dx.doi.org/10.1109/ICCITECHN.2010.5723901

Kadir, A., Nugroho, L.E., Susanto, A., \& Santosa, P. I. (2011). A comparative experiment of several shape methods in recognizing plants. Int. J. Comput. Sci. Inform. Technol., 3(3), $256-263$. http://dx.doi.org/10.5121/ijcsit.2011.3318

Kadir, A., Nugroho, L. E., Susanto, A., \& Santosa, P. I. (2012). Performance improvement of leaf identification system using principal component analysis. International Journal of Advanced Science and Technology, 44, 113-124.

Kaiser, H. F. (1960). The application of electronic computers to factor analysis. Educational and Psychological Measurement, 20(1), 141-151. http://dx.doi.org/10.1177/001316446002000116

Kochummen, K. M., \& Rusea, G. (2000). Tree Flora of Sabah and Sarawak (Vol. 3, pp. 181-334).

Lansky, E. P., \& Paavilainen, H. M. (2011). Figs: The Genus Ficus. London New York: CRC Press Boca Raton.

Lee, C. L., \& Chen, S. Y. (2006). Classification of leaf images. International Journal of Imaging Systems and Technology, 16(1), 15-23. http://dx.doi.org/10.1002/ima.20063

Najjar, A., \& Zagrouba, E. (2012). Flower image segmentation based on color analysis and a supervised evaluation. Proceedings of the Communications and Information Technology, 397-401. http://dx.doi.org/10.1109/ICCITechnol.2012.6285834

Nihayah, M., Yong, K. W., \& Nur Faizah, A. B. (2012). Determination of mineral content in the Ficus deltoidea leaves. Jurnal Sains Kesihatan Malaysia, 10(2), 25-29.

Norhaniza, A., Sin, C. Y., Chee, E. S., Nee, K. I., \& Renxin, L. (2007). Blood glucose lowering effect of Ficus deltoidea aqueous extract. Malaysian Journal of Science, 26(1), 73-78.

O’Rourke, N., Hatcher, L., \& Stepanski, E. J. (2005). A step-by-step approach to using SAS for univariate \& multivariate statistics. SAS Publishing.

Ramlan, A. A. (2003). Turning Malaysia into a global herbal producer: A personal perspective. Retrieved from http://www.penerbit.utm.my/syarahan/pdf/09/siri9_teks.pdf

Rencher, A. C. (2002). Methods of Multivariate Analysis. Wiley-Interscience. 
Sulaiman, M. R., Hussain, M. K., Zakaria, Z. A., Somchit, M. N., Moin, S., Mohamad, A. S., \& Israf, D. A. (2008). Evaluation of the antinociceptive activity of Ficus deltoidea aqueous extract. Fitoterapia, 79(7-8), 557-561. http://dx.doi.org/10. 1016/j.fitote.2008.06.005

Turner, I. M. (1995). Catalogue of the vascular plants in Malaya. Garden's Bulletin Singapore (Vol. 47, pp. 347-757). Singapore Botanic Gardens.

USDA (2007). ARS, National Genetic Resources Program, Germplasm Resources Information Network - (GRIN) Database. Retrieved from http://ars-grin.gov/cgi-bin/npgs/html/taxon.pl?16826

Wu, S. G., Bao, F. S., Xu, E. U., Wang, Y. X., Chang, Y. F., \& Xiang, Q. L. (2007). A leaf recognition algorithm for plant classification using probabilistic neural network. Proceedings of the Signal Processing and Information Technology, 11-16. http://dx.doi.org/10.1109/ISSPIT.2007.4458016

Zulkifli, Z., Puteh, S., \& Mohtar, I. A. (2011). Plant leaf identification using moment invariants and general regression neural network. Proceedings of the Hybrid Intelligent Systems, 430-435. http://dx.doi.org/10.1109/HIS.2011.6122144

\section{Copyrights}

Copyright for this article is retained by the author(s), with first publication rights granted to the journal.

This is an open-access article distributed under the terms and conditions of the Creative Commons Attribution license (http://creativecommons.org/licenses/by/3.0/). 